\title{
Staphylococcus schleiferi subsp. coagulans
}

National Cancer Institute

\section{Source}

National Cancer Institute. Staphylococcus schleiferi subsp. coagulans. NCI Thesaurus.

Code C124405.

A subspecies of Staphylococcus schleiferi that is coagulase tube test positive, produces betahemolysin and a heat-stable nuclease but not a clumping factor. This subspecies has not been isolated from humans. 